\title{
Successful Application of Tissue Engineering Skin to Third Degree Burn Wound on Lateral Thorax: A Case Study
}

\author{
Jon Kee Ho, Huawei Shao, Chuangang You, Xuanliang Pan, Xingang Wang, Guoxian Chen, Abidullah \\ Khan and Chunmao Han*
}

Department of Burns and Wound Care, Second Affiliated Hospital of Zhejiang University, School of Medicine, Jiefang Road 88, Hangzhou 310009, China

*Corresponding author: Chunmao Han, Department of Burns and Wound Care, Second Affiliated Hospital of Zhejiang University, School of Medicine, Jiefang Road 88, Hangzhou 310009, China

\begin{tabular}{|c|c|}
\hline ARTICLE INFO & ABSTRACT \\
\hline 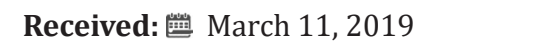 & Wounds on lateral thorax are hard to repair for its location makes skin-grafting a \\
\hline Published: 幽 March 28, 2019 & \\
\hline $\begin{array}{l}\text { Citation: Jon Kee Ho, Huawei Shao, } \\
\text { Chuangang You, Xuanliang Pan, Xingang } \\
\text { Wang, Guoxian Chen, Abidullah Khan, } \\
\text { Chunmao Han. Successful Application } \\
\text { of Tissue Engineering Skin to Third } \\
\text { Degree Burn Wound on Lateral Thorax: }\end{array}$ & $\begin{array}{l}\text { double layers containing epidermal cells and fibroblasts. It is mainly used for graft treat- } \\
\text { ment of burns. The case in this study grafted ActivSkin }{ }^{\circledR} \text { to third degree burns on the left } \\
\text { thoracic wounds created after escharotomy. The grafted area was about } 100 \mathrm{~cm}^{2} \text {, and four } \\
\text { ActivSkin }{ }^{\circledR} \text { patches }\left(20 \mathrm{~cm}^{2} / \text { patch) were used in the treatment. The grafts survived on }\right. \\
\text { the wound, and the epithelialization of the wound in area with ActivSkin }{ }^{\circledast} \text { was faster than } \\
\text { other area without it. Seven weeks later, foreign genes were not detected on the wound. } \\
\text { The patient was almost completely healed at day } 76 \text { after application of ActivSkin }{ }^{\circledR} \text {. }\end{array}$ \\
\hline
\end{tabular}

Keywords: Skin tissue engineering; Burn; Skin grafting

\section{Introduction}

As burn treatment rapidly evolves, early closure, skin repair, functional recovery and cosmetic improvement become major goals in this field. When a burn area is large, skin autografting is usually inapplicable due to limited donor site and the resultant secondary trauma [1]. In addition, heterograft or allograft might cause rejection. Therefore, in vitro constructed skin has become an ideal wound dressing. An ideal wound dressing is not only supposed to be responsive to the cells at molecular level, but also bio-degradable and absorbable [2]. The dressing materials are supposed to fit the surrounding environment of the affected area, stimulate the cellular proliferation and differentiation, and extracellular matrix synthesis [3]. ActivSkin ${ }^{\circledR}$ is tissue engineering skin derived from infant foreskin cells, which have been subjected to in vitro proliferation. Those cells were first frozen and stored, then seeded to natural extracellular scaffolds, with the epithelial cells further seeded on their wound. After culture, they form a double-layered tissue engineering skin. The structure of such skin includes both the epithelial layer and dermal layer, extremely like that of the normal skin. Each layer contains a certain number of skin cells and therefore can well cover the grafted area and improve the healing. The present study described a successful application of the tissue engineering skin (ActivSkin ${ }^{\circledR}$ ) to the deep burn on lateral thorax.

\section{Materials and Methods}

The patient was a 32-year-old, male, Chinese. He was $173 \mathrm{~cm}$ tall, weighed $75 \mathrm{~kg}$ with a BMI of 25.06. He suffered multiple burn injuries when the bus he was on caught fire and was later admitted to the intensive care unit (ICU). He was evaluated and diagnosed with total burn surface area (TBSA) of 95\%; 85\% of which were third degree burn, partly sparing the head, back, lower abdomen and buttocks. Between day 3 and day 76 after the injury, he underwent a total of 13 surgeries, of which 9 surgeries involved the harvesting of scalp skin for grafting. Microskin grafting technique was applied, a combination of autograft and allograft, embedded graft, and mesh graft (1:2 or 1:3), were carried out to repair the affected wound. At day 76 after the injury, the grafted area was almost completely healed $(<1 \%$ of TBSA). 
Considering the extent of his burn injury, donor sites were insufficient, his left lateral thoracic wound were subjected to escharotomy to expose the granulating wound during Week 4 after the injury and four active human tissue engineering skin patches $\left(20 \mathrm{~cm}^{2} /\right.$ patch, Shaanxi Aierfu Tissue Engineering Company Limited, lot number: 140702) were grafted (Figure 1). Biopsy was performed on the same day of the grafting surgery and the result images were taken. The graft survivals were observed and imaged at $2^{\text {nd }}, 3^{\text {rd }}$, and $4^{\text {th }}$ week after the surgery $\left(6^{\text {th }}, 7^{\text {th }}\right.$, and $8^{\text {th }}$ week after the injury) along with biopsies. Hematoxylin-eosin (HE) staining was performed to observe the skin survivals. To further confirm that the grafts stayed on the wound, during week 7 after the surgery (week 11 after the injury), the healed skin tissues and oral mucosa from the patient were collected and sent to Zhejiang Dian Forensic Center for DNA homology test (Figure 2A). The test protocol was as below: DNA was prepared using Chelex method and amplified using the accredited Goldeneye 20A system. The amplicons were separated using the ABI-3000 electrophoresis system and the genotyping results were laser-scanned and analyzed.

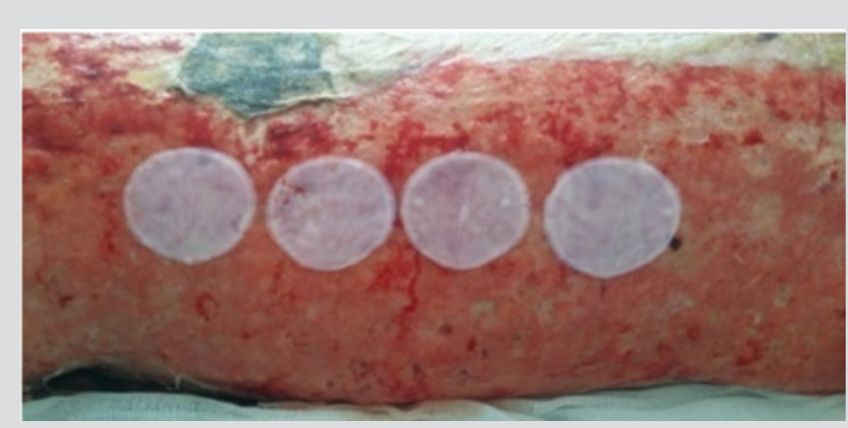

Figure 1: Four ActivSkin ${ }^{\circledR}$ human tissue engineering skin patches were transplanted on the granulation wound.

\section{Results}

\section{Clinical examinations}

During Week 2 after the graft surgery, the skin appeared grayish while the unaffected skin appeared pink (Figure 2B). Histology showed the migration of the epithelial cells in the grafted area. Ungrafted area had rich blood vessels with large amount of red blood cells. During Week 3 after the surgery, the grayish area disseminated and radiated to form patches. Histology showed proliferated epithelial matrix that covered the dermis and a large number of inflammatory cells in the tissue. During Week 4, the affected areas were almost pale, and red stretches appeared. Histology showed the proliferated epithelial matrix and epidermis with distinct granular layer (Figure 2C). Some cells migrated to the wound for keratinization. The collagen structure in the dermis layer was similar to that in the normal skin and the inflammatory cells disappeared (Figure 2D). All the 19 gene loci including D19S433 were human genetic markers. They were collectively used for the homology test. Their collective identification capacity is $>1 \times 10^{9}$ in Chinese (Han) ethnic. The above results from the 19 STR genetic loci and AMEL sexual locus showed that the two specimens were identical. Accord- ing to the STR data in Chinese Han ethnic, the likelihood ratio was calculated to be $1.6757 \times 1025$. Therefore, apart from the possibility of the specimens are from twins, the identicality indicated that the grafts were not detected on the healed wound (Table 1).

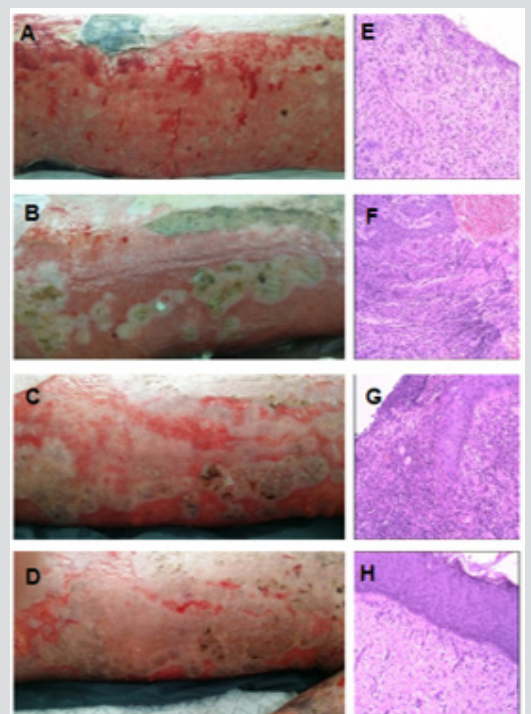

Figure 2: (A, E) Gross observation of left granulation wound after escharotomy and HE is staining. (B-D, F-H) Gross observation of the wounds after the ActivSkin ${ }^{\circledR}$ graft surgery for 2-4 weeks.

Table 1: DNA homology and typing test results.

\begin{tabular}{|c|c|c|}
\hline STR Locus & WMS & WMS (S) \\
\hline D19S433 & $14 / 15.2$ & $14 / 15.2$ \\
\hline D5S818 & $11 / 12$ & $11 / 12$ \\
\hline D21S11 & $29 / 33$ & $29 / 33$ \\
\hline D18S51 & $13 / 19$ & $13 / 19$ \\
\hline D6S1043 & $12 / 13$ & $12 / 13$ \\
\hline D3S1358 & $15 / 17$ & $15 / 17$ \\
\hline D13S317 & $8 / 12$ & $8 / 12$ \\
\hline D7S820 & $10 / 11$ & $10 / 11$ \\
\hline D16S539 & $9 / 12$ & $9 / 12$ \\
\hline CSF1P0 & $10 / 12$ & $10 / 12$ \\
\hline Pente D & $9 / 12$ & $9 / 12$ \\
\hline AMEL & X/Y & X/Y \\
\hline vWA & $17 / 19$ & $17 / 19$ \\
\hline D8S1179 & $13 / 14$ & $13 / 14$ \\
\hline TP0X & $8 / 8$ & $8 / 8$ \\
\hline Penta E & $5 / 14$ & $5 / 14$ \\
\hline TH01 & $9 / 9$ & $9 / 9$ \\
\hline D12S391 & $18 / 21$ & $18 / 21$ \\
\hline D2S1338 & $17 / 22$ & $17 / 22$ \\
\hline FGA & $20 / 22$ & $20 / 22$ \\
\hline & & \\
\hline & & \\
\hline
\end{tabular}

\section{Discussion}

ActivSkin $^{\circledR}$ is derived from two types of human skin cells: epidermal cells and fibroblast cells. These cells and collagen 
matrix were collectively used to construct the double-layer tissue engineering skin (Figure 3A). The dermal layer is the natural collagen scaffolds and the fibroblast cells grow inside those scaffolds. The epidermal layer consists multiple epidermal cells and the surface is the keratinized epidermal structure (Figure 3B). Gap structures were occasionally observed at the connections between the epidermis and dermis. Transmission electron microscope (TEM) showed that the intercellular epidermal bridge connections were visible, and the dermal fibroblast cells were surrounded by sparsely distributed collagen or collagen bundles which were secreted by fibroblast cells (Figure 3C). There are many advantages such as manipulability and ease of use, painless and noninvasive procedures, and well-tolerated that could improve wound healing rate. Furthermore, with the absence of rejection responses or other adverse responses, it would reduce the treatment duration and pain at the grafted areas compared with the conventional treatment protocol. According to the studies by M. Griffiths on Apligraf, which is similar to the ActivSkin ${ }^{\circledR}$, after being used for acute wound healing, the dressing material could stay on the grafted wound for short period (4 weeks, generally) and the foreign DNA could not be detected after 6 weekspost-surgery [4]. Only when chronic venous ulcer occurred did the fibroblast cells exist for a longer period of time at the acceptor sites [5]. In this study, ActivSkin ${ }^{\circledR}$ was grafted onto the wounds after escharotomy. With blood supply, nutrition, exudation from wound bed and stimulatory factors, the graft could survive for a short period of time [6]. After 7 weeks, allogeneic cells might have been replaced with the autologous cells or phagotcytized by the immune cells. In this study, the ActivSkin ${ }^{\circledR}$ application allowed faster wound keratinization compared with wound without $\operatorname{ActivSkin}^{\circledR}$, and the possible mechanisms were:
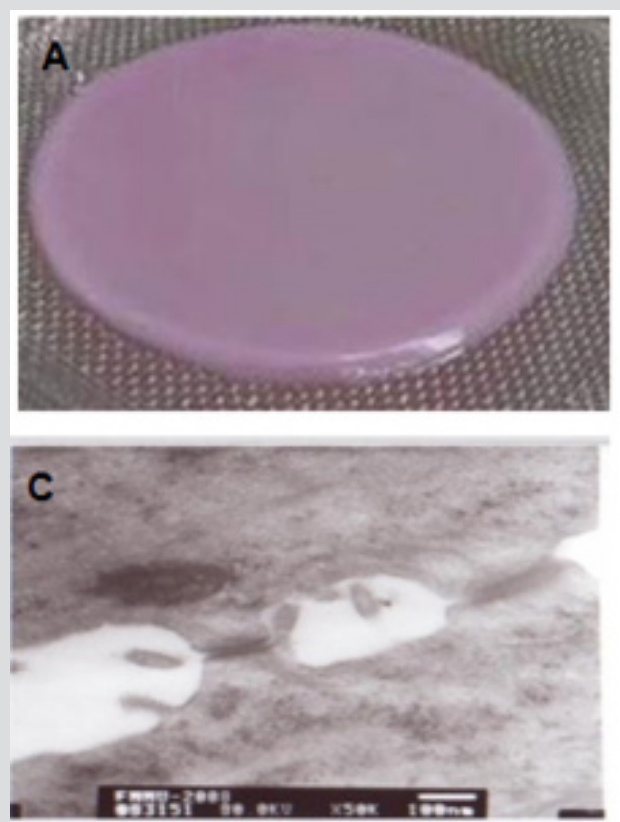
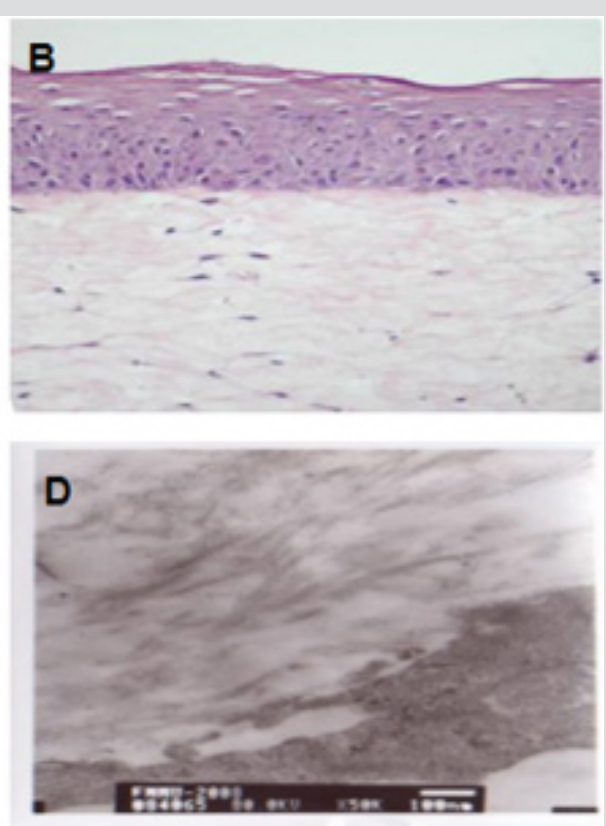

Figure 3:

A. View of ActivSkin ${ }^{\circledR}$,

B. Histology sections of ActivSkin ${ }^{\circledR}$,

C. TEM images of ActivSkin ${ }^{\circledR}$

a) ActivSkin ${ }^{\circledR}$ collagen provided structured space for the patient's autologous cells and promoted their proliferation and migration.

b) $\quad$ ActivSkin $^{\circledR}$ cells secreted numerous growth factors such as EGF, aFGF, bFGF, and ECGF, which stimulated the fibroblast cells and epidermal cells to further secrete IL-6 and IL-8 [7].

These two factors and TNF/HGF collectively stimulated the proliferation of the autologous basal fibroblast cells and capillaries to improve the wound healing (angiogenesis, tissue proliferation and tissue restructure) and epithelialization of wound [8]. In this study, the graft sites were third degree burn wound at the lateral thorax followed by escharotomy. In third degree burn wound after the escharotomy, there may still be some residual hair follicle tissues left. The hair follicle stem cells (multi-potential stem cells) in the outer root sheath might differentiate into the epidermal stem cells and epidermal cells and proliferate, resulting in island-like epithelialization on the grafted wound [9]. Such possibility could not be ruled out. ActivSkin ${ }^{\circledR}$ is one of the few tissues engineered product in the market. In terms of its structure and theoretical practice, it could improve the healing of all acute and chronic wounds. The clinical application of such engineering skin has been rarely reported and the mechanisms behind need further investigation and on a larger scale to have statistical significance. 


\section{Acknowledgement}

The tissue engineered skin was donated by Shaanxi Aierfu Tissue Engineering Company Limited. This study was financially supported by the National key research and development project (2016YFC1100800), and the National Natural Science Foundation of China $(81671909,81772069)$ and Natural Science Foundation of Zhejiang Province, China (LY15H150004, LQ16H150002).

\section{References}

1. Willard JJ, Drexler JW, Das A, Roy S, Shilo S, et al. (2013) Plant-Derived Human Collagen Scaffolds for Skin Tissue Engineering. Tissue Eng Part A 19(13-14): 1507-1518.

2. Wu Z, Fan L, Xu B, Lin Y, Zhang P, et al. (2015) Use of Decellularized Scaffolds Combined with Hyaluronic Acid and Basic Fibroblast Growth Factor for Skin Tissue Engineering. Tissue Eng Part A 21: 390-402.

3. Biedermann T, Boettcher Haberzeth S, Reichmann E (2013) Tissue Engineering of Skin for Wound Coverage. Eur J Pediatr Surg 23: 375-382.
4. Griffiths M, Ojeh N, Livingstone R, Price R, Navsaria H (2004) Survival of Apligraf in Acute Human Wounds. Tissue Eng 10: 1180-1195.

5. Cooper ML, Hansbrough JF, Spielvogel RL, Ron Cohen, Ronnda LB, et al. (1991) In vivo Optimization of a Living Dermal Substitute Employing Cultured Human Fibroblasts on a Biodegradable Polyglycolic Acid or Polyglactin Mesh. Biomaterials 12(2): 243-248.

6. Hayward CJ, Fradette J, Morissette MP, Rina Guignard, Lucie Germain, et al. (2014) Using Human Umbilical Cord Cells for Tissue Engineering: A Comparison with Skin Cells. Differentiation 87(3-4): 172-181.

7. Mohd HA, Halim AS (2015) Vital Roles of Stem Cells and Biomaterials in Skin Tissue Engineering. World J Stem Cells 7: 428-436.

8. Miller KJ, Brown DA, Ibrahim MM, Ramchal TD, Levinson H (2015) MicroRNAs in Skin Tissue Engineering. Adv Drug Deliv Rev 88: 16-36.

9. Szabo AZ, Fong S, Yue L, Zhang K, Strachan LR, et al. (2013) The CD44+ $\mathrm{ALDH}^{+}$Population of Human Keratinocytes is Enriched for Epidermal Stem Cells with Long-Term Repopulating Ability. Stem Cells 31: 786-799.

\section{ISSN: 2574-1241}

DOI: 10.26717/BJSTR.2019.16.002868

Chunmao Han. Biomed J Sci \& Tech Res

This work is licensed under Creative Commons Attribution 4.0 License

Submission Link: https://biomedres.us/submit-manuscript.php

$\begin{array}{ll}\text { BIOMEDICAL } & \text { Assets of Publishing with us } \\ \text { RESEARCHES } & \text { Global archiving of articles } \\ & \text { - Immediate, unrestricted online access } \\ & \text { - Rigorous Peer Review Process } \\ \end{array}$

